\title{
A BEHAVIORAL FinANCE MODEL OF THE EXCHANGE RATE WITH MANY FORECASTING RULES
}

\author{
PAUL DE GRAUWE \\ PABLO ROVIRA KALTWASSER
}

CESIFO WORKING PAPER NO. 1849

CATEGORY 6: MONETARy POLICY AND INTERnATIONAL FINANCE NOVEMBER 2006

An electronic version of the paper may be downloaded

- from the SSRN website:

- from the RePEc website:

www.SSRN.com

- from the CESifo website:

www.RePEc.org

www.CESifo-group.de 


\title{
A BeHAVIORAL FinANCE MOdEL OF THE EXCHANGE RATE WITH MANY FORECASTING RULES
}

\begin{abstract}
This paper presents a behavioral finance model of the exchange rate. Agents forecast the exchange rate by means of very simple rules. They can choose between three groups of forecasting rules: fundamentalist, extrapolative and momentum rules. Agents using a fundamentalist rule are not able to observe the true value of the fundamental exchange and therefore have to rely on an estimate of this variable to make a forecast. Based on simulation analysis we find that two types of equilibria exist, a fundamental and a non-fundamental one. Both the probability of finding a particular type of equilibrium and the probability of switching between different types of equilibria depend on the number of rules available to agents. Furthermore, we find that the exchange rate dynamics is sensitive to initial conditions and to the risk perception about the underlying fundamental. Both results are dependent on the number of forecasting rules.
\end{abstract}

JEL Code: F31, C53.

Paul De Grauwe

University of Leuven

Department of Economics

Naamsestraat 69

3000 Leuven

Belgium

paul.degrauwe@econ.kuleuven.be
Pablo Rovira Kaltwasser

University of Leuven

Department of Economics

Naamsestraat 69

3000 Leuven

Belgium

pablo.rovirakaltwasser@econ.kuleuven.be

October 16, 2006

We thank Volker Böhm and Kristien Smedts for valuable comments. We are also gratefully indebted to the Research Foundation - Flanders (FWO) for financial support. 


\section{Introduction}

During the last few years, models of the exchange market have increasingly departed from the rational expectations efficient market paradigm. The main reason for this departure is the poor empirical performance of models based on that paradigm. This has led to new modelling approaches that start from the fact that agents experience cognitive problems preventing them from understanding the complexity of the world (Frankel and Froot(1990), Brock and Hommes(1998), Lux and Marchesi(1998), Brunnermeier(2001), Kirman and Theyssière(2002), De Grauwe and Grimaldi(2005), Lux and Schorstein(2005)). As a result, agents rely on simple behavioral rules (heuristics) that incorporate only small bits of the total information set. In this paper we follow this recent trend and we refine some previous modelling approaches.

The new modelling approach in which agents have imperfect information, maintains the notion of rationality. Rationality, however, is to be understood as an evolutionary selection mechanism. Instead of defining it as the capacity to understand the complexity of the world, as is done in rational expectations models, we use the notion of rationality as a mechanism whereby agents evaluate their past decisions according to a "fitness" criterion and revise those as new information becomes available. This way of understanding rationality comes closer to the view that utility has not only an ex-ante component which drives agents in their process of making decisions, but it also refers to the hedonic experience associated with an outcome as stressed by Kahneman and Thaler(2006). In order to maximize their utility, fully rational individuals need to be able to make precise and unbiased forecasts of hedonic outcomes of alternative choices. As these authors show, this condition is not always satisfied. On the contrary, individuals often make systematic errors in predicting the utility they will obtain from future outcomes. As a consequence they will repeatedly miss the objective of maximizing (experienced) utility. Since agents make systematic mistakes when forecasting the utility of future outcomes they are obliged to revise their decision so as to maximize utility. But agents can only know ex-post whether their choice increased their utility or not. If it did not, they will correct their decision. Thus, rationality is to be understood as an evolutionary process. We apply this notion of rationality in this paper by allowing agents to use simple behavioral rules to forecast the exchange rate. If a particular rule does not pass a 
fitness (profitability) test, agents will switch to another rule in order to obtain greater fitness (return). ${ }^{1}$

The objective of this paper is twofold. We analyze how increasing the number of forecasting rules available to agents affects the dynamics of the exchange rate. In addition, we assume that agents are not able to observe the underlying value of the fundamental exchange rate. They face uncertainty about this variable and therefore they need to estimate it. Our results can be summarized as follows. First, two types of equilibria are found, a fundamental and a non-fundamental (bubble) one. Whether the exchange rate is in a fundamental or in a non-fundamental equilibrium is determined by stochastic disturbances. The number of forecasting rules does not affect this finding. Second, the exchange rate dynamics is sensitive to initial conditions. Initial disturbances have a large impact on the path of the exchange rate. When agents have many rules to chose from this sensitivity to initial conditions disappears. Third, once a particular equilibrium has been reached, the probability of switching to another equilibrium depends on the number of rules. Fourth, we find that the uncertainty (risk perception) about the fundamental exchange rate is important in the determining the path of the exchange rate. Fourth, we find that the exchange rate series presents excess volatility. Fifth, for certain combinations of parameter values we find that the exchange rate is dominated by chaos dynamics. The range, though, for which we are able to find this chaothic behavior is rather small. The remaining of the paper is organized as follows. In section 2 we present the theoretical model. In sections 3 and 4 we analyze the characteristics of the model in a stochastic environment. The features of the model in a deterministic environment are analyzed in section 5 . In section 6 we study the sensitivity to initial conditions and in section 7 we investigate the relevance of the uncertainty about the fundamental exchange rate. We conclude in section 8

\section{Theoretical exchange rate model}

The model presented in this section is an extension of the model developed by De Grauwe and Grimaldi (2005). We extend this model in two directions. First, instead of assuming

\footnotetext{
${ }^{1}$ This approach is akin to the idea of bounded rationality. See $\operatorname{Simon}(1957)$, Sargent(1993) and Thaler(1994).
} 
that agents can only choose among two forecasting rules, we now assume that they can select among $\mathrm{N}$ different rules. Second, we drop the assumption that agents who use a fundamentalist rule know the value of the underlying fundamental exchange rate with certainty. Here we assume that they face uncertainty about this fundamental value. The rest of the model has the same structure as in De Grauwe and Grimaldi (2005). There is a constant number of agents, each one of them choosing an optimal portfolio consisting of a domestic and a foreign asset. The only uncertainty in this choice comes from the unknown future developments of the exchange rate. Every agent makes a forecast of the future exchange rate by means of a "rule of thumb" forecasting rule at the beginning of the period. After each period, all agents evaluate their ex-ante choice of selecting a particular forecasting rule using a fitness criterion, i.e. by comparing the realized (ex-post) risk adjusted return delivered by this rule with the average (ex-post) risk adjusted returns obtained with the alternative rules. If the fitness criterion does not favour the use of the rule anymore agents switch to a "fitter" rule.

\subsection{The optimal portfolio}

We assume agents of different types $k$ depending on their beliefs about the future exchange rate. Each agent can invest in two assets, a domestic (risk-free) asset and a foreign (risky) asset. The agents' utility function can be represented by the following equation:

$$
U\left(W_{t+1}^{k}\right)=E_{t}\left(W_{t+1}^{k}\right)-\frac{1}{2} \mu V^{k}\left(W_{t+1}^{k}\right)
$$

where $W_{t+1}^{k}$ is the wealth of an agent using rule of type $k$ to forecast the exchange rate for period $t+1, E_{t}$ is the expectation operator, $\mu$ is the coefficient of risk aversion and $V^{k}\left(W_{t+1}^{k}\right)$ represents the conditional variance of wealth of agent using rule $k$, and $k=1, . . K{ }^{2}$ The wealth dynamics is governed by:

$$
W_{t+1}^{k}=\left(1+r^{*}\right) s_{t+1} d_{t}^{k}+(1+r)\left(W_{t}^{k}-s_{t} d_{t}^{k}\right)
$$

where $r$ and $r^{*}$ are respectively the domestic and the foreign interest rates (which are known with certainty), $s_{t+1}$ is the exchange rate at time $t+1, d_{k, t}$ represents the holdings of the foreign assets by agent using rule type $k$ at time $t$. Thus, the first term on the right-hand

\footnotetext{
${ }^{2}$ The functional form of the different forecasting rules will be specified in the next section.
} 
side of equation 2 represents the value of the (risky) foreign portfolio expressed in domestic currency at time $t+1$ while the second term represents the value of the (riskless) domestic portfolio at time $t+1 .^{3}$

Substituting equation 2 in 1 and maximizing the utility with respect to $d_{k, t}$ allows us to derive the standard optimal holding of foreign assets by agents using a forecasting rule of type $k:{ }^{4}$

$$
d_{k, t}=\frac{\left(1+r^{*}\right) E_{t}^{k}\left[s_{t+1}\right]-(1+r) s_{t}}{\mu \sigma_{k, t}^{2}}
$$

where $\sigma_{k, t}^{2}=\left(1+r^{*}\right)^{2} V_{t}^{k}\left(s_{t+1}\right)$. The optimal holding of the foreign asset depends on the expected excess return (corrected for risk) of the foreign asset. The market demand for foreign assets at time $t$ is the sum of the individual demands, i.e.:

$$
\sum_{k=1}^{K} n_{k, t} d_{k, t}=D_{t}
$$

where $n_{k, t}$ is the number of agents using rule of type $k$ at period $t$.

Market equilibrium implies that the market demand is equal to the market supply $Z_{t}$ which we assume to be exogenous. ${ }^{5}$ Thus,

$$
Z_{t}=D_{t}
$$

Substituting the optimal holdings into the market demand and then into the market equilibrium equation and solving for the exchange rate $s_{t}$ yields the market clearing exchange rate:

$$
s_{t}=\left(\frac{1+r^{*}}{1+r}\right) \frac{1}{\sum_{k=1}^{K} \frac{w_{k, t}}{\sigma_{k, t}^{2}}}\left[\sum_{k=1}^{K} w_{k, t} \frac{E_{t}^{k}\left[s_{t+1}\right]}{\sigma_{k, t}^{2}}-\Omega_{t} Z_{t}\right]
$$

where $w_{k, t}=\frac{n_{k, t}}{\sum_{k=1}^{K} n_{k, t}}$ is the weight (share) of agent using rule type $k$, and $\Omega_{t}=\frac{\mu}{\left(1+r^{*}\right) \sum_{k=1}^{K} n_{k, t}}$.

\footnotetext{
${ }^{3}$ The model could be interpreted as an asset pricing model with one risky asset (e.g. shares) and a risk free asset. Equation (2) would then be written as

$W_{t+1}^{i}=\left(s_{t+1}+y_{t+1}\right) d_{t}^{i}+(1+r)\left(W_{t}^{i}-s_{t} d_{t}^{i}\right)$

where $s_{t+1}$ is the price of the share in $\mathrm{t}+1$ and $y_{t+1}$ is the dividend per share in $\mathrm{t}+1$.

${ }^{4}$ If the model is interpreted as an asset pricing model of one risky asset (shares) and a risk free asset, the corresponding optimal holding of the risky asset becomes

$d_{i, t}=\frac{E_{t}^{i}\left(s_{t+1}+y_{t+1}\right)-(1+r) s_{t}}{\mu \sigma_{i, t}^{2}}$

${ }^{5}$ The market supply is determined by the net current account and by the sales or purchases of foreign exchange of the central bank. We assume both to be exogenous here. In De Grauwe and Grimaldi 2006 a model with endogenized current account is presented.
} 
Thus the market clearing exchange rate is determined by the forecasts of the agents, $E_{t}^{k}$, about the future exchange rate. Note also that the forecasts are weighted by their respective variances $\sigma_{k, t}^{2}$. When agents' $k$ forecasts have a high variance the weight of these agents in the determination of the market exchange rate is reduced. In the following we will set $r=r^{*}$.

\subsection{Forecasting rules}

Agents can choose between $K$ different rules to forecast the exchange rate. We distinguish between three classes of rules: fundamental, extrapolative and momentum rules. There are respectively $F, C$ and $M$ versions of fundamental, extrapolative and momentum rules. Therefore:

$$
K=\left(f_{1}+f_{2}+\ldots+f_{F}\right)+\left(c_{1}+c_{2}+\ldots+c_{C}\right)+\left(m_{1}+m_{2}+\ldots+m_{M}\right)
$$

where $f_{i}, c_{i}$ and $m_{i}$ stand for the $i$-th version of the fundamentalist, chartist and momentum rules respectively.

Fundamentalists ${ }^{6}$ make their forecasts by comparing the market exchange rate with the fundamental value of the exchange rate. As mentioned earlier, they do not know the fundamental value with certainty, however. As a result, agents have to rely on an estimate of this variable. The forecasting rule for fundamentalists is therefore given by:

$$
E_{t}^{f_{i}}\left[\Delta s_{t+1}\right]=-\psi\left(s_{t-1}-s_{f_{i}, t-1}^{*}\right)
$$

where $s_{f_{i}, t-1}^{*}$ is fundamentalist's $i$ estimate of the value of the fundamental exchange rate in period $t-1$, and $0<\psi<1$. Even though agents using a fundamentalist rule have heterogeneous estimates of the value of the fundamental exchange rate, they all use a mean reverting rule to forecast the exchange rate. Put differently, if an agent using fundamentalist rule $k$ observes that the market exchange rate exceeds (is below) his estimate of the fundamental, $s_{f_{i}, t-1}^{*}$, she will expect the market exchange rate to decline (increase) towards the "fundamental" next period. The parameter $\psi$ expresses the percentage of the estimated misalignment (i.e. $s_{t-1}-s_{f_{i}, t-1}^{*}$ ) expected to be corrected next period. Note that as since agents may have different estimates of the fundamental exchange rate, they will tend to take

\footnotetext{
${ }^{6}$ We use the term "fundamentalist" in a loose sense. It is an agent whos chooses to use a fundamentalist forecasting rule.
} 
opposite positions when the exchange rate does not move too far from the true fundamental. We show the way in which agents form their estimates of the fundamental exchange rate in the following section. The (unobserved true) fundamental exchange rate is assumed be driven by a random walk process. ${ }^{7}$

We define two types of chartist forecasting rules. The first one is an extrapolating rule while the second one a momentum rule. The extrapolating rule consists in extrapolating the past changes of the exchange rate into the future. It takes the following simple form:

$$
E_{t}^{c_{i}}\left[\Delta s_{t+1}\right]=\beta_{c_{i}} \Delta s_{t-1}
$$

where $\beta_{c_{i}}$ is the extrapolating parameter used by chartist $c_{i}$.

The second, is a momentum rule to forecast the exchange rate. It consists in first computing the difference between a short-term and a long-term moving average of past observed values of the market exchange rate. If the short-term moving average is larger (smaller) than the long-term moving average agents expect the future exchange rate to increase (decline). Formally:

$$
E_{t}^{m_{i}}\left[\Delta s_{t+1}\right]=\beta_{m i}\left(s t m a_{t-1}-l t m a_{t-1}\right)
$$

where:

$$
\begin{aligned}
s t m a_{t-1} & =\frac{\sum\left(s_{t-1}+s_{t-2} \ldots+s_{t-N_{S}}\right)}{N_{S}} \\
l t m a_{t-1} & =\frac{\sum\left(s_{t-1}+s_{t-2} \ldots+s_{t-N_{L}}\right)}{N_{L}}
\end{aligned}
$$

are the short-term and long-term moving averages and $N_{S}<N_{L}$

Finally, equation 6 also depends on the risk of investing in the foreign portfolio. Risk is defined as the variance of the one period ahead forecast errors made by the agents. Since

\footnotetext{
${ }^{7}$ To check for robustness we also allowed in some simulation the fundamental to follow a mean reverting (AR) process. Since the results under both definitions of the fundamental were not different we decided to maintin our original assumption of a random walk process driving the fundamemtal.
} 
agents make different forecasts, the risks involved differ. We obtain the following expressions: ${ }^{8}$

$$
\begin{gathered}
\sigma_{f_{i}, t+1}^{2}=\left(E_{t}^{f_{i}}\left[s_{t+1}\right]-s_{t+1}\right)^{2} \\
\sigma_{e_{i}, t+1}^{2}=\left(E_{t}^{e_{i}}\left[s_{t+1}\right]-s_{t+1}\right)^{2} \\
\sigma_{m_{i}, t+1}^{2}=\left(E_{t}^{m_{i}}\left[s_{t+1}\right]-s_{t+1}\right)^{2}
\end{gathered}
$$

\subsubsection{Fitness of the rules}

The next step in our analysis is to specify how agents evaluate the fitness of their forecasting rules. The general idea that we follow here is that agents choose one of the available rules, then compare ex post the (risk adjusted) returns of this rule with the alternatives, after which they decide whether to keep the rule or switch to another one. Thus, as motivated in the introduction, our model is in the logic of evolutionary dynamics. Agents make a choice ex-ante. Once the outcome of their choice is observable they evaluate whether their choice produced a higher profit than the benchmark profit. When this is not the case agents revise their decisions and switch to a to a more profitable forecasting rule.

In order to implement this idea we use the approach proposed by Brock and Hommes(1997) which consists in making the weights of the forecasting rules a function of the relative (risk adjusted) returns of these rules, i.e.. ${ }^{9}$

$$
\begin{aligned}
w_{f_{i}, t} & =\frac{\exp \left[\gamma \pi_{f_{i}, t}^{\prime}\right]}{\sum_{k=1}^{K}\left(\exp \left[\gamma \pi_{k, t}^{\prime}\right]\right)} \\
w_{c_{i}, t} & =\frac{\exp \left[\gamma \pi_{c_{i}, t}^{\prime}\right]}{\sum_{k=1}^{K}\left(\exp \left[\gamma \pi_{k, t}^{\prime}\right]\right)}
\end{aligned}
$$

\footnotetext{
${ }^{8}$ Here we implicitly assume that agents remember only the risk associated with the last period's decision. A memory parameter can be easily added in order to allow agents to have a longer memory horizon. In De Grauwe and Grimaldi (2006), for instance, agents' memory is the weighted average of all past variances and the weights are assumed to decay exponentially, i.e. agents attach a higher weight to recent mistakes and lower weight to mistakes that lie further in the past.

${ }^{9}$ This specification of the decision rule is often used in discrete choice models. For an application in the market for differentiated products see Anderson, de Palma, and Thisse(1992). The idea has also been applied in financial markets, by Brock and Hommes (1997), by Lux(1998) and by Lux and Marchesi (1999).
} 


$$
w_{m_{i}, t}=\frac{\exp \left[\gamma \pi_{m_{i}, t}^{\prime}\right]}{\sum_{k=1}^{K}\left(\exp \left[\gamma \pi_{k, t}^{\prime}\right]\right)}
$$

where $\pi_{f_{i}, t}^{\prime}, \pi_{c_{i}, t}^{\prime}$ and $\pi_{m_{i}, t}^{\prime}$ are the risk adjusted net returns made by the use of the different forecasting rules. Note that $\pi_{f_{i}, t}^{\prime}=\pi_{f_{i}, t}-\mu \sigma_{f_{i}, t}^{2}, \pi_{c_{i}, t}^{\prime}=\pi_{c_{i}, t}-\mu \sigma_{e_{i}, t}^{2}$ and $\pi_{m_{i}, t}^{\prime}=\pi_{m_{i}, t}-\mu \sigma_{m_{i}, t}^{2}$.

Equations 16 , 17 and 18 can be interpreted as switching rules. When the risk adjusted return of a particular rule increases relative to the risk adjusted return obtained from the other rules (the denominator), then the share of agents who use that rule increases, and vice versa. The motivation to use such a switching mechanism is the following: agents observe their environment and react to economic variables by adjusting their behavior with a certain probability that is a function of those economics variables. In our model, the economic variable that drives these changes in agents' behavior is the ex-post (risk-adjusted) return of their investment in the foreign exchange market. The parameter $\gamma$ measures the intensity with which agents revise their forecasting rules. With an increasing $\gamma$ agents react strongly to the relative returns of the rules. In the limit when $\gamma$ goes to infinity all agents choose the forecasting rule which proves to be the most profitable. When $\gamma$ is equal to zero agents are insensitive to the relative return of the rules. Thus, $\gamma$ is a measure of inertia in the decision to switch to the more profitable rule. ${ }^{10}$ As will be seen, this parameter is of great importance in generating bubbles.

We define the return as the one-period return of investing $1 \$$ in the foreign asset. More formally,

$$
\begin{gathered}
\pi_{k, t}=\left[s_{t}\left(1+r^{*}\right)-s_{t-1}(1+r)\right] \operatorname{sgn}\left[\left(1+r^{*}\right) E_{t-1}^{k}\left[s_{t}\right]-(1+r) s_{t-1}\right] \\
\text { where } \operatorname{sgn}[x]=\left\{\begin{array}{cl}
1 & \text { for } x>0 \\
0 & \text { for } x=0 \\
-1 & \text { for } x<0
\end{array} \text { and } k=1 \ldots K\right.
\end{gathered}
$$

Thus, when agents forecasted an increase in the exchange rate and this increase is realized, their per unit profit is equal to the observed increase in the exchange rate (corrected for the interest differential). If instead the exchange rate declines, they make a per unit loss which

\footnotetext{
${ }^{10}$ The psychological literature reveals that there is a lot of evidence of a "status quo bias" in decision making (see Kahneman, Knetsch and Thaler(1991). This implies $\gamma<\infty$. Thus we set $0<\gamma<\infty$.
} 
equals this decline (because in this case they have bought foreign assets which have declined in price).

We use a concept of return instead of profits for two reasons. First, our switching rules of equations 17, 16 and 18 select the fittest rules. It does not select agents. Second, in our definition of returns agents only have to use publicly available information, i.e. the forecasting rules and the observed exchange rate changes. They do not have to know their competitor's profits. Furthermore, the profit obtained by taking a certain position are a function of the amount invested which is not public knowledge in our model. Here we assume that every agent invests only $\$ 1$ and therefore the profits are to be interpreted as the percentage return obtained by taking a particular position.

\section{Stochastic simulation of the model}

The strong non-linearities make it difficult to characterize the equilibrium and the dynamics of the model in an analytical way. Therefore, we use simulation techniques which we will present in this and the following sections. We select "reasonable" values of the parameters, i.e. those that come close to empirically observed values. However, we will analyze how sensitive the solution is to different sets of parameter values in the following section.

We start by presenting simulations in the time domain. We concentrate first on how the number of forecasting rules affects the equilibrium and the dynamics around the equilibrium. At the start of each simulation half of the agents choose a fundamentalist rules and half choose a chartist rule (either extrapolative or momentum rule). Since the fundamental value is not known with certainty each agent using a fundamentalist rule estimates the value of the underlying fundamental. The estimates of the fundamental are given by a normally distributed random sequence with mean equal to the true fundamental (which varies at every period $t$ due to the fact that the fundamental is driven by a random walk process) and with variance equal to $\sigma_{\text {fund }}^{2}$. In section 7 we analyze the importance of parameter $\sigma_{\text {fund }}^{2}$ which is a measure of the uncertainty about the true underlying fundamental. Unless it is otherwise indicated we assume that this variance takes the value of 1 . The fundamental estimates as well as the fundamental itself are generated before every simulation begins.

Agents using an extrapolative rule or a momentum rule choose a value for $\beta_{e_{i}}$ and $\beta_{m_{j}}$ 
that is taken from within the following bounds: $\beta_{e_{i}} \in[0.5 ; 1.0], \beta_{m_{j}} \in[0.25 ; 0.5]$. Values of $\beta_{e_{i}}>1$ and $\beta_{m_{j}}>0.5$ produce unstable results. In section 5 we perform a sensitivity analysis with respect to these parameter values. Agents are allowed to switch between these different rules depending on their relative profitabilities as specified in equations 16,17 and 18 .

We show the results for two different values of the number of rules $\mathrm{N}$, i.e. $\mathrm{N}=4$ (Figure 1a and $1 b$ ) and $\mathrm{N}=200$ (Figure $2 \mathrm{a}$ and $2 \mathrm{~b}) .{ }^{11}$ The main feature of these simulations is that the exchange rate movements are characterized by the existence of two regimes.

Figure 1: Simulations in the time domain with $\mathrm{N}=4$

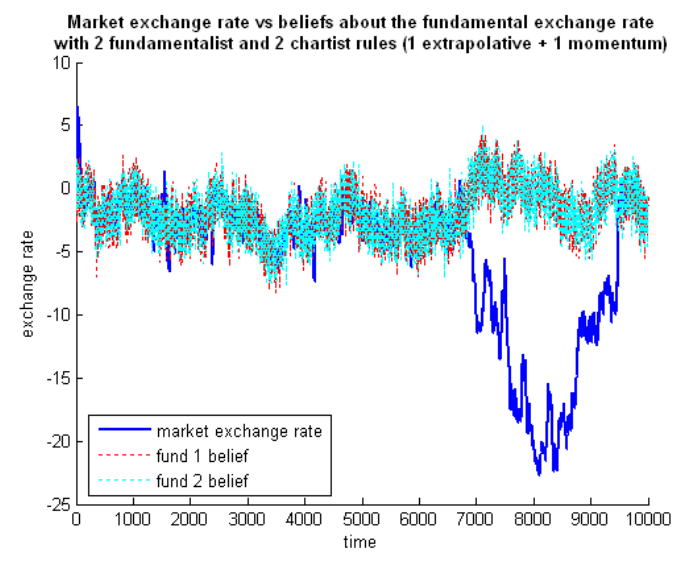

$1 \mathrm{a}$

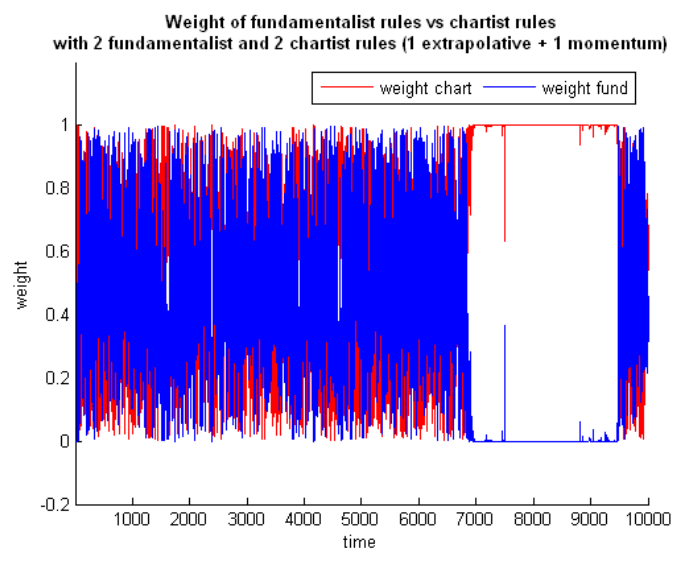

$1 b$

The first regime is one during which the exchange rate moves within a close band around the fundamental given by the beliefs (estimates) of agents about the fundamental exchange rate; the second regime is characterized by movements that are disconnected from the fundamental. The former regime coincides with a situation where both chartists and fundamentalists rules are used (see right hand side panel of figures 1 and 2 which shows the weights of chartist and fundamentalist rules), while the second regime coincides with a situation where only chartist rules are used. In appendix A we show that the model generates two types of equilibria, a fundamental and a non-fundamental one. The non-fundamental equilibrium is one where fundamentalist rules are not used, and only chartist rules are employed. This equilibrium arises because when certain stochastic shocks arise, chartist rules can become

\footnotetext{
${ }^{11}$ We only show the belief of 5 fundamentalists when agents can choose between 5 or more fundamentalist rules.
} 
Figure 2: Simulations in the time domain with $\mathrm{N}=100$

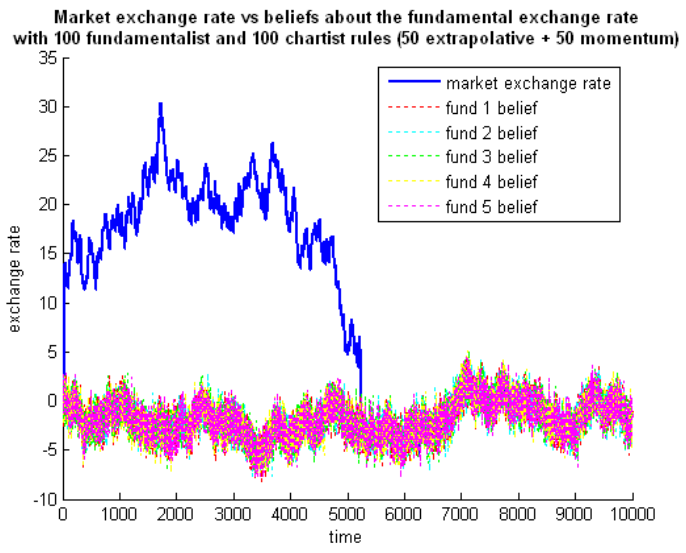

$2 \mathrm{a}$

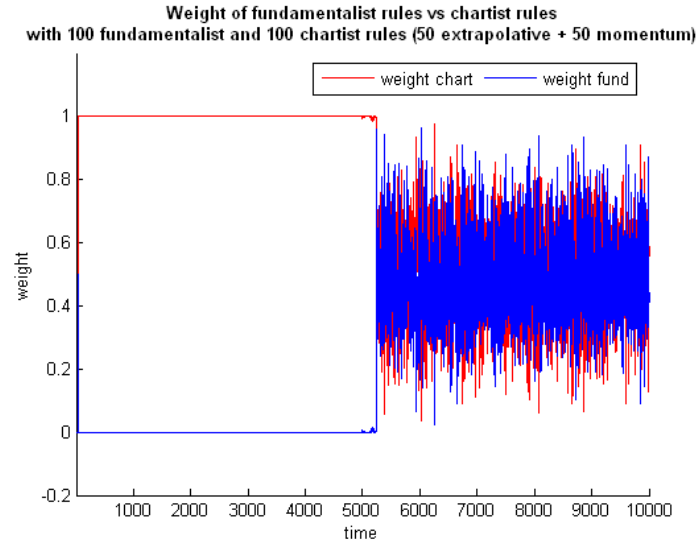

$2 \mathrm{~b}$

very profitable, thereby inducing agents who use fundamentalist rules to switch to chartist rules. This then reinforces the profitability of the latter rules, inducing more switches. A selffulfilling dynamics is created in which the exchange rate is attracted to a non-fundamental equilibrium, which can also be called a bubble equilibrium. ${ }^{12}$ The latter, however, is only locally stable. Sufficiently strong shocks in the fundamental will attract the exchange rate towards the fundamental equilibrium. This feature of the model creates movements of the exchange rate around the fundamental whereby the exchange rate appears to be disconnected from its fundamental value much of the time. We found a similar result in De Grauwe and Grimaldi(2005) when only two types of rules were allowed. Thus the existence of two types of equilibria, a fundamental and a non-fundamental one, continues to hold when the number of rules is expanded beyond 2 .

\section{Sensitivity analysis in a stochastic environment}

In this section we report on experiments that aim to find out how robust the previous results are. We want to check the sensitivity of the results to particular parameter values, and to the size of shocks. We performed simulations in the time domain (10,000 periods) for many

\footnotetext{
${ }^{12}$ It should be stressed that this definition of a bubble is very different from the "rational bubble" which is defined as an unstable path of the exchange rate. It comes closer to the notion of "sunspots" which is also an equilibrium concept in rational expectations models (see Blanchard and Fischer(1989), p255).
} 
different parameter values and sizes of initial shocks. We dropped the first 4,000 observations in order to eliminate the transient effects of the initial shock itself. We counted the number of times the model produces a non-fundamental (bubble) equilibrium. The latter is defined as a situation in which the share of agents using a fundamentalist rule is zero (more precisely was smaller or equal to $2^{-52}$ ). Each simulation with a given value of parameter $\gamma$ and initial shock, is repeated 100 times.

The probability of finding a bubble, conditional on the values the different parameters beta, gama and the shock to initial conditions, is obtained by computing the average of the percentage of times that bubbles occur in each of the 100 simulations. We collect these numbers in figure 3a (2 fundamentalist and 2 chartist rules) and figure 3b (100 fundamentalist and 100 chartist rules). The vertical axis shows the percentage of time the exchange rate is in a bubble equilibrium. The $\mathrm{x}$-axis shows the initial disturbance given to the exchange rate; the $\mathrm{y}$-axis shows different values of the parameter $\gamma$ (which measures the intensity agents switch to a different rule when profitability changes).

We obtain broadly similar results whether we have two rules or many rules. This can be seen by comparing figures $3 \mathrm{a}$ and $3 \mathrm{~b}$. When both $\gamma$ and the shock to initial conditions are close to zero, bubbles do not occur. This is a world in which agents do not switch. In such a world the exchange rate remains close to its fundamental value. We note though that in the case of many rules the area of fundamental equilibria is larger. This suggests that we need larger shocks to produce non-fundamental equilibria when agents scan choose among many rules that when they choose among two rules only.

As $\gamma$ increases, i.e. agents are increasingly willing to switch to more profitable rules, the probability of obtaining bubbles increases. This result holds both when agents choose among few or many rules.

\section{Sensitivity analysis in a deterministic environment.}

In this section we analyze the nature of the equilibria of the model when the stochastic shocks are zero. This deterministic version of the model allows us to shed some additional light on the nature of the two types of equilibria uncovered in the previous section. In order to do so, we set all exogenous stochastic variables equal to zero, and normalized the fundamental 


\section{Figure 3: Probabilities of finding bubbles}

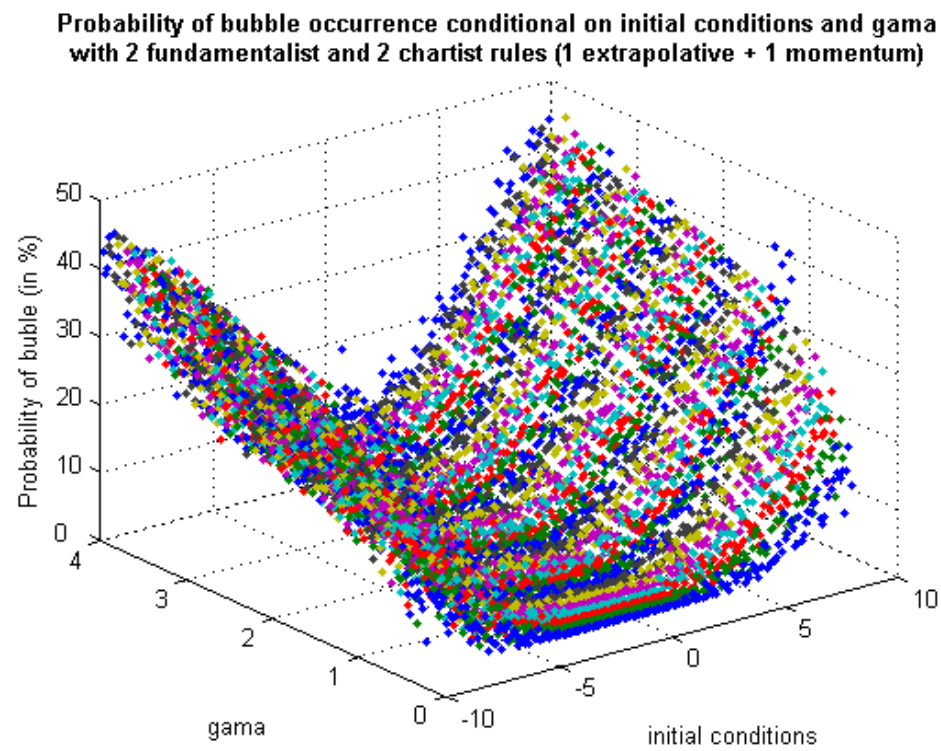

$3 \mathrm{a}$

Probability of bubble occurrence conditional on initial conditions and gama with 100 fundamentalist and 100 chartist rules (1 extrapolative +1 momentum)

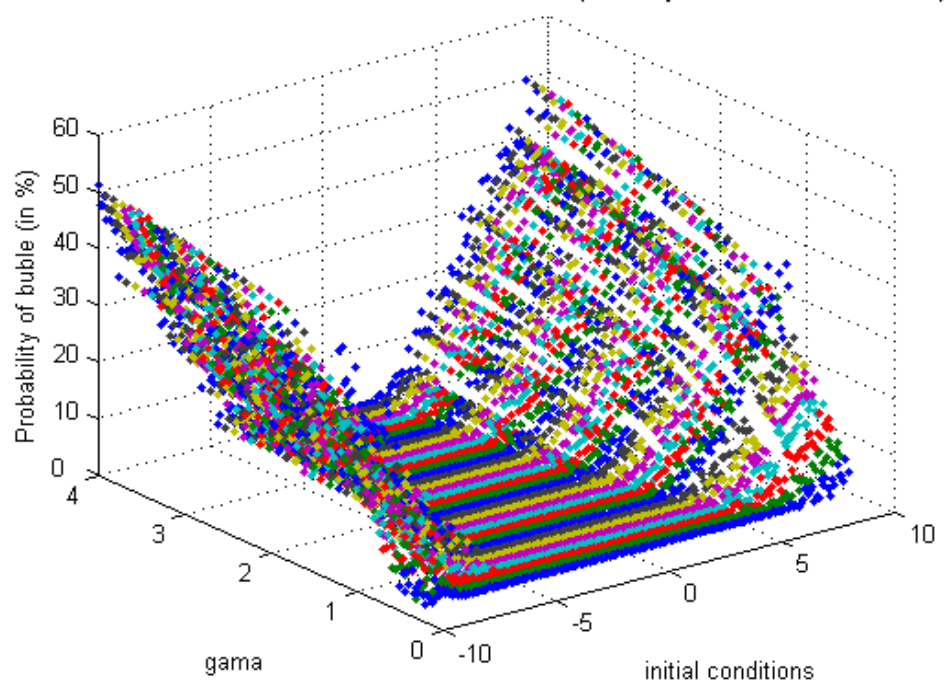

$3 \mathrm{~b}$ 
value of the exchange rate at 0 . We then simulated the model giving different initial shocks to the exchange rate and different values to $\gamma, \beta_{c}$ or $\beta_{m}$. We ran these simulations over 10000 periods in order to analyze if the exchange rate converges to its equilibrium. This can be either a fundamental equilibrium or a non-fundamental (bubble) equilibrium. In the former case the exchange rate converges to zero (which is the value given to the constant fundamental value). In the case of a bubble equilibrium the exchange rate converges to a positive or negative number. In this case all agents use chartist rules, and nobody uses fundamentalist rules. We show the results of these experiments in figures 4 to 6 . On the vertical axis we set out the equilibrium value of the exchange rate (obtained from simulations in the time domain). On the x-axis we present the initial shock of the exchange rate, and on the y-axis the different values of a specific parameter $\left(\gamma\right.$ in figure $4, \beta_{e}$ in figure 5 and $\beta_{m}$ in figure 6). The results show that for small initial shocks the exchange rate always converges to its fundamental value. This is made clear from the fact that all the equilibrium exchange rates are located on a plane that cuts the vertical axis at the value of zero.

\section{Figure 4: Deterministic simulation: sensitivity to gama and initial conditions}

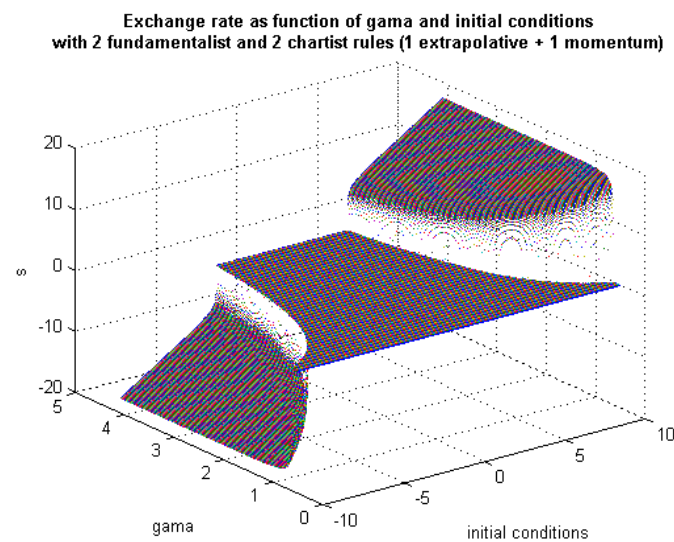

$4 \mathrm{a}$

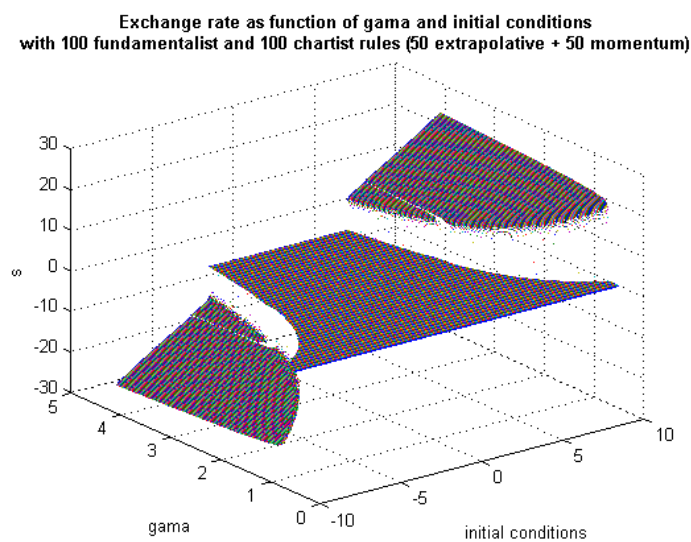

$4 \mathrm{~b}$

We also observe that as the parameters $\gamma, \beta_{e}$, and $\beta_{m}$ increase, the number of nonfundamental equilibria increases. This is shown by the collection of positive and negative points. Each of these points represents a non-fundamental equilibrium to which the exchange rate converges when the initial shock and the parameters $\gamma, \beta_{e}$ and $\beta_{m}$ are sufficiently large. Notice that when these parameters increase in value the initial shock that will lead to a 
Figure 5: Deterministic simulations: sensitivity to beta-extrapolative and initial conditions with 2 fundamentalists and 2 chartists

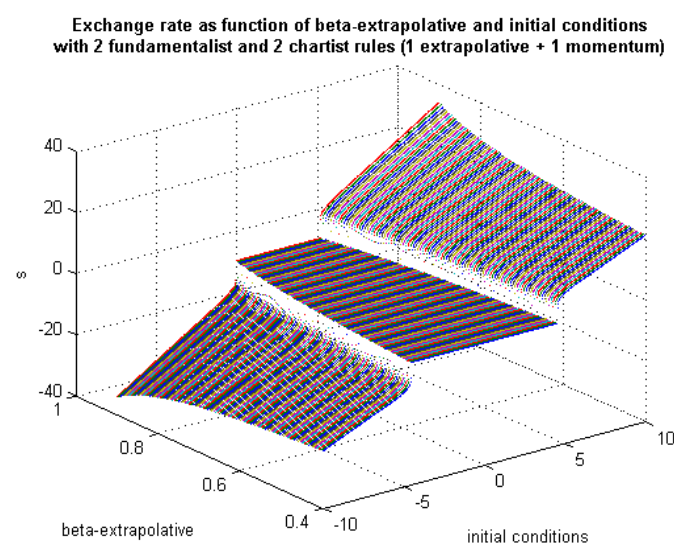

$5 \mathrm{a}$

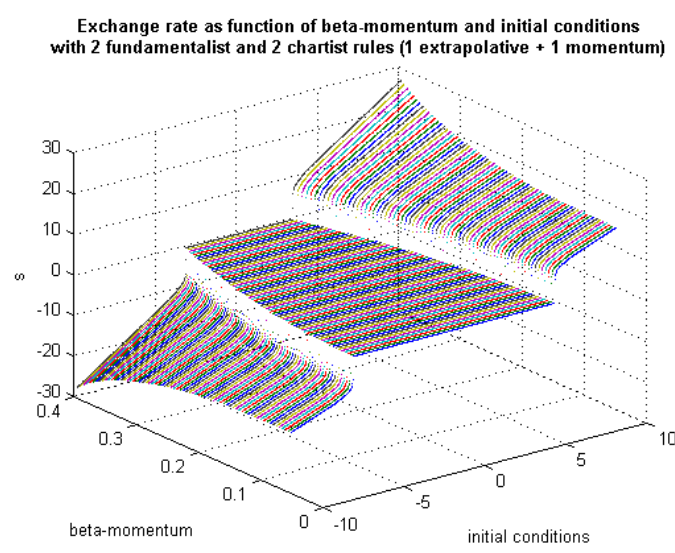

$5 b$

Figure 6: Deterministic simulations: sensitivity to beta-momentum and initial conditions with 100 fundamentalists and 100 chartists

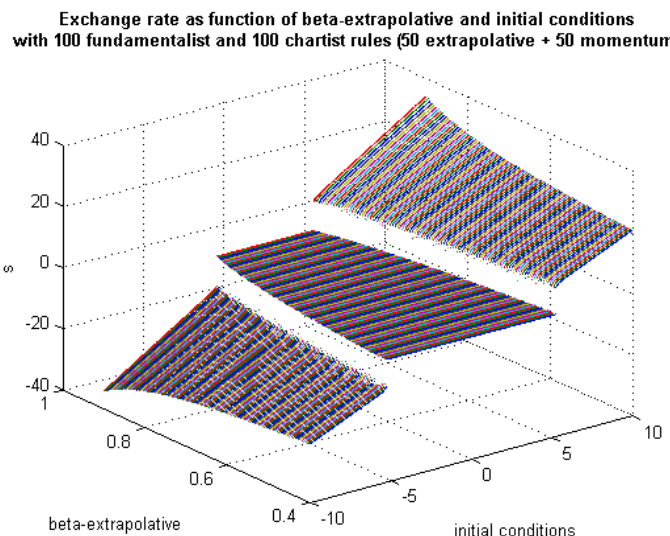

$6 \mathrm{a}$

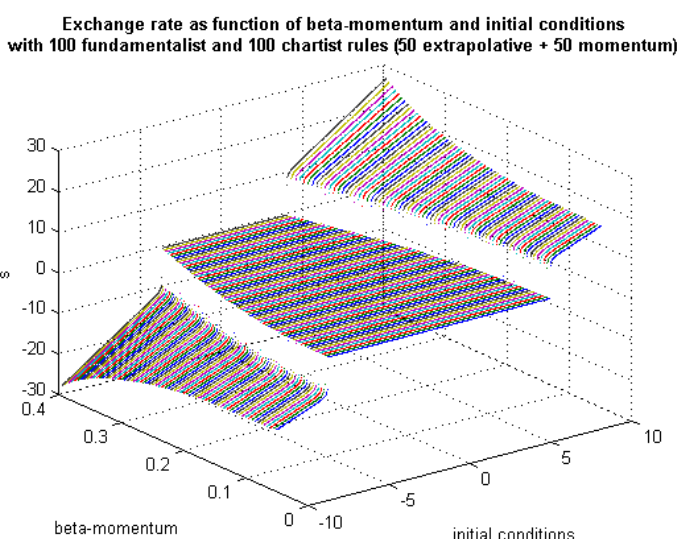

$6 \mathrm{~b}$ 
bubble equilibrium becomes smaller. Note also that the border between fundamental and non-fundamental equilibria is discontinuous. We will show that it has a fractal nature, which leads to "sensitivity to initial conditions". We will return to this feature in section 6 .

As can be seen from comparing the left and right panels of figures 4 to 6 the results are broadly similar in the two cases of few and many rules. However, the planes collecting the fundamental equilibria tend to be larger when agents have a choice among many rules, rather than two. This confirms our result of the previous section indicating that one needs larger shocks to trigger a bubble when agents use many rules than when they use only a few.

It should also be noted that a non-fundamental equilibrium can only exist and be model consistent if nobody uses fundamentalist forecasting rules in equilibrium. Suppose the contrary, i.e. the exchange rate has converged to a constant non-fundamental equilibrium while some agents continue to use a fundamentalist rule. In this case these agents would be forecasting an increase (or a decline) in the exchange rate. Since in equilibrium the exchange rate is constant these agents would make a permanent and perfectly predictable forecast error. The model excludes this as an equilibrium outcome. The fitness criterion ensures that such a rule will not be used.

\section{Sensitivity to initial conditions}

The fractal nature of the boundary between fundamental and non-fundamental equilibria creates the potential for sensitivity to initial conditions. This implies that a very small difference in the initial disturbance to the exchange rate can lead to a different time path of the exchange rate for long periods of time. We analyze the existence of sensitivity to initial conditions by repeating two times a simulation of the model in the time domain while assuming exactly the same realization of the fundamental exchange rate and beliefs about the fundamental exchange rate, as well as the same random shock to the market exchange rate. The only difference between the two simulations is the fact that the initial exchange rate is given a very small different value. We show the results of this experiment in figure 7 .

We find that when the number of rules is small the exchange rate is extremely sensitive to initial conditions while when the number of rules is large this feature disappears and the two exchange rate series coincide perfectly. The rationale for this result is that when there are 
Figure 7: Sensitivity to initial conditions in the time domain

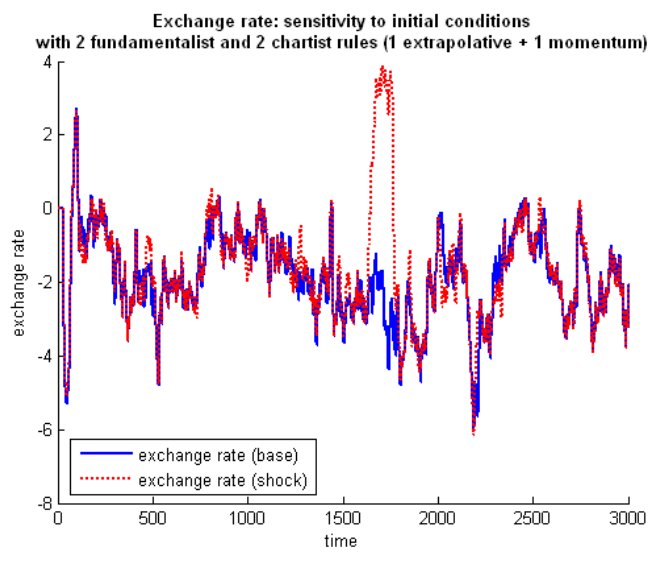

$7 \mathrm{a}$

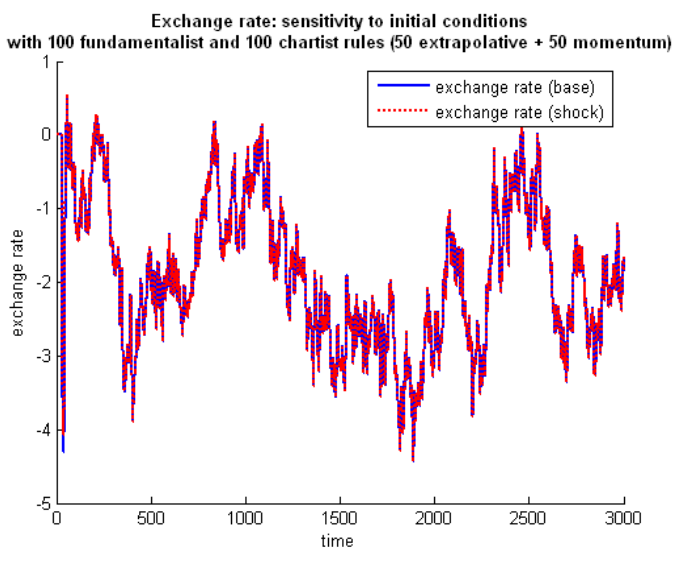

$7 \mathrm{~b}$

Figure 8: Sensitivity to initial conditions: percentage of times initial conditions generate different paths of the exchange rate

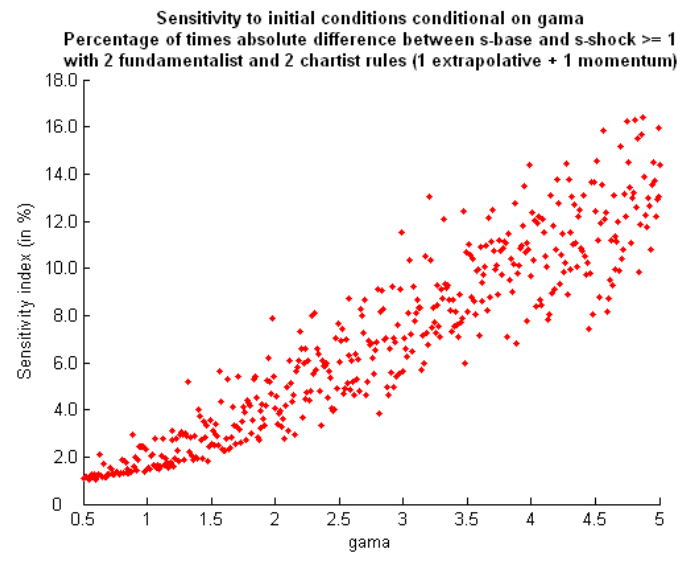

$8 \mathrm{a}$

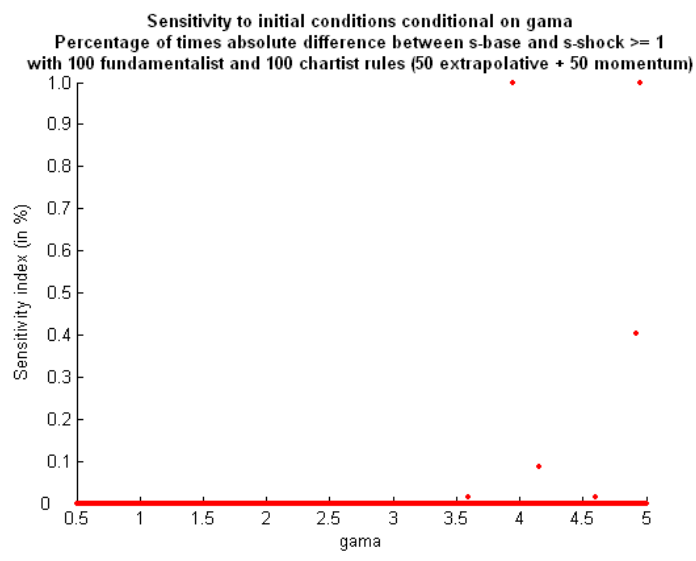

$8 \mathrm{~b}$ 
fewer rules to choose from the discontinuities in the switching process are more pronounced. These discontinuities are at the core of the sensitivity to initial conditions feature.

In order to be sure that this result is robust we repeated the same experiment many times for different values of parameter $\gamma$. In each simulation we counted the number of times the deviation between the two exchange rates exceeded a treshold value which we set at 1 . Every simulation with a given combination of $\gamma$ and shock to initial condition was repeated 100 times over 10,000 periods. We eliminate the first 4,000 thousand observations eliminate the transient effect of the initial shock itself. We show the results in figure 8. The horizontal axis shows the value of parameter $\gamma$. Each point on the vertical axis shows the percentage of times the two exchange rates realizations deviated by more than the threshold value. We observe that when agents have many rules to choose from, the two exchange rates series are perfectly aligned, i.e. the sensitivity to initial conditions disappears. Since the number of rules available to agents is larger the discontinuities in the switches become less pronounced. Put differently, the probability of jumping (switching) between regimes is lower when agents have many rules to choose from.

Figure 9: Percentage of times the exchange rate entered or left a bubble

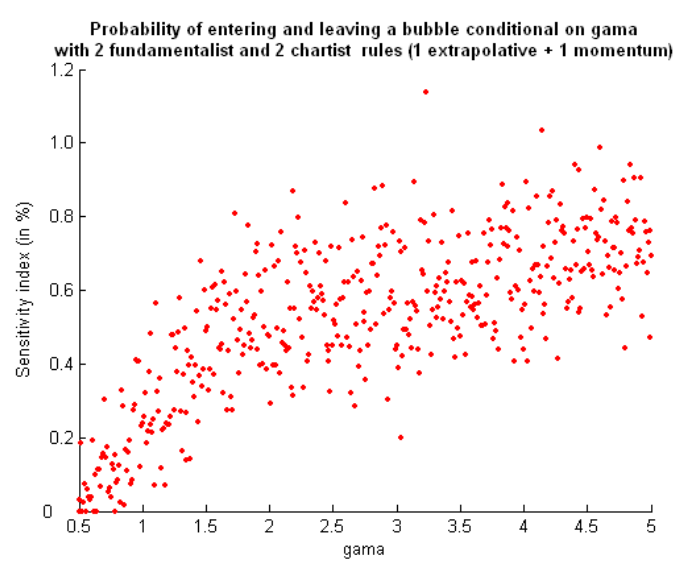

$9 \mathrm{a}$

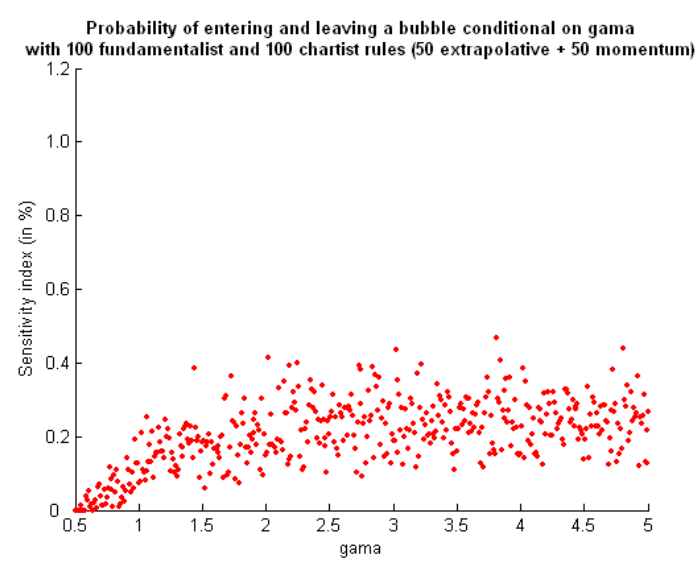

$9 \mathrm{~b}$

In figure 9 we present this in more detail where the probability of entering or leaving a bubble equilibrium is shown. We simulated the model in the time domain over 10,000 periods for a given initial shock (-8) while letting $\gamma$ increase. ${ }^{13}$ After eliminating the first

\footnotetext{
${ }^{13}$ This value was arbitrarily chosen. The conculssions, however, do not depend on this particular initial
} 
4,000 thousand observations we computed the average number of times that the exchange rate moved into and out of a bubble equilibrium. The same experiment was repeated 100 times and then the average over this 100 repetitions was computed. By comparing figure 9a and $9 \mathrm{~b}$ it is possible to see that the probability of entering and leaving a bubble increases with gama. When agents can choose between few rules (figure 9a), though, this probability is considerably higher compared to a situation where agents have many rules (figure $9 \mathrm{~b}$ ). In the latter case discreteness of switches between alternative forecasting rules becomes less pronounced due to the larger choice of rules available to agents. As a consequence the number of times the exchange rate enters and/or leaves a particular equilibrium is lower the larger the number of rules available to agents.

\section{Uncertainty about the fundamental}

Agents who use a fundamentalist forecasting rule face the uncertainty about the true value of the underlying fundamental value of the exchange rate. It is important to analyze how this uncertainty affects the model and the dynamics of the exchange rate. We analyze this issue now.

As will be remembered fundamentalists estimate the underlying fundamental. The way we proceed here is to assume different levels of precision with which agents estimate the true fundamental. We do this by varying the standard deviation of the distribution of the estimated fundamental around the true value while leaving the random shock as well as the initial shock to the observed exchange rate unchanged. Thus when agents feel less confident about their estimate of the fundamental exchange rate, the standard deviation increases. We show the effect of increasing the standard deviation in the time domain in figures 10a and 10b. In 10a the standard deviation is low $(\operatorname{std}=1)$, in $10 \mathrm{~b}$ it is high $(\operatorname{std}=3) \cdot{ }^{14}$

The most surprising aspect of the results of figures 10a and 10b is the extreme sensitivity of the exchange rate path with respect to the standard deviation. The simulations were run in such a way that the stochastic realization of the true fundamental is exactly the same

shock and remain valid for other parameter values.

${ }^{14}$ We eliminate the first 3000 thousand observations because they are highly biased by the initial shock to the exchange rate. Focusing at the remaining observations delivers a better insight about the path of the exchange rate independent of this shock. 
Figure 10: Sensitivity to the variance of the estimate of the fundamental with few rules

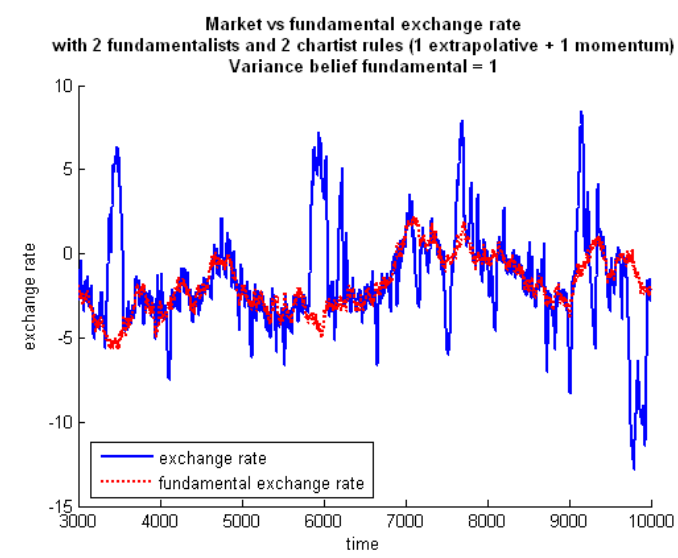

$10 \mathrm{a}$

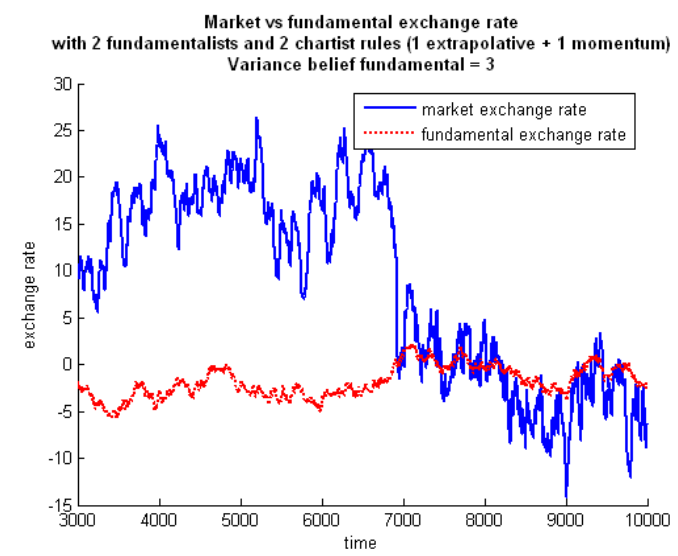

$10 \mathrm{~b}$

Figure 11: Sensitivity to the variance of the estimate of the fundamental with many rules

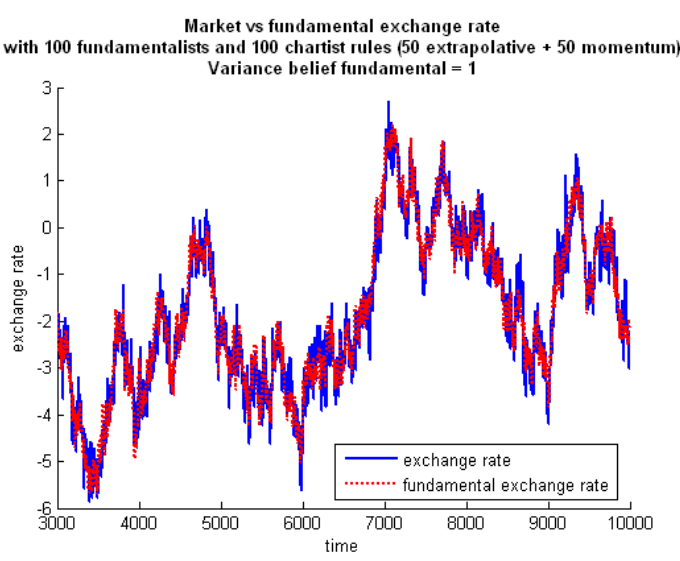

$11 \mathrm{a}$

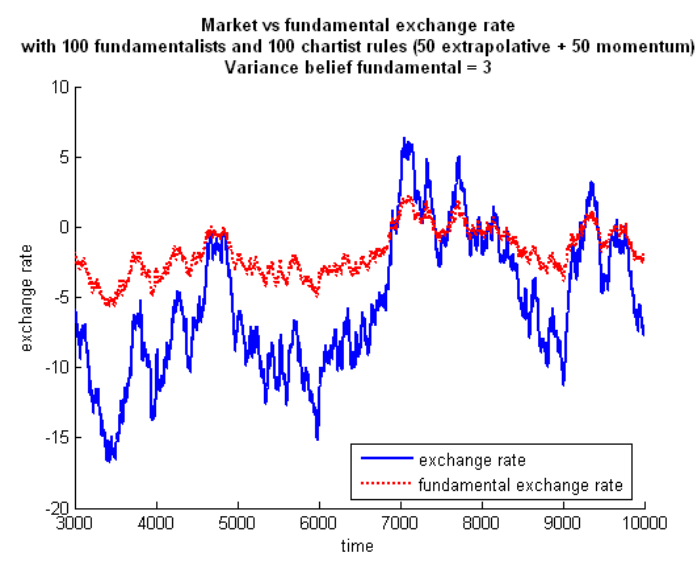

$11 \mathrm{~b}$ 
in the two simulations as well as the stochastic shock to the observed exchange rate. The only difference is in the standard deviation of the estimates of this fundamental made by agents. We observe that the time path of the exchange rate is completely different in the two simulations although the underlying true fundamental is behaving in exactly the same way. Thus uncertainty about the underlying fundamental has a strong effect on the course of the exchange rate movements.

As can be seen from figures 11a and 11b, we obtain a similar result when agents have a choice between many rules (100 fundamentalist and 100 chartist rules). Also in this situation we find that the exchange rate path crucially depends on the uncertainty agents have about the true value of the fundamental exchange rate. We note however that when the uncertainty is low (figure 11a) the exchange rate remains in a close neighborhood of the fundamental. This was not the case when the number of forecasting rules to choose from is small (see figure 10a).

Another interesting feature that is present in our results is that the volatility of the observed exchange rate is substantially higher than the volatility of the fundamental exchange rate. Thus our results mimick the empirical regularity of excess volatility. We also find though that when the number of rules is large and when there is little uncertainty about the underlying fundamental the excess volatility is less pronounced. The intuition behind this result is the same as in the previous section. When there are more rules available to agents the discontinuities in the switches are attenuated. As a consequence large jumps in the exchange rate are less frequent.

\section{Conclusion}

The rational expectations revolution has dominated macroeconomics and exchange rate modelling during the last three decades. Things are changing, though. As a result of the poor empirical performance of the exchange rate models based on rational expectations, the use of models that depart from rational expectations has become acceptable again.

In this paper we departed from the rational expectations paradigm. This does not mean, however, that agents in our model are fools. The rational expectations paradigm has given a very restrictive meaning to the concept of rationality. This is one in which agents are 
capable of understanding the incredible complexity of the world and are using this God-like intellectual capacity to compute the implications of policy actions. We use a different concept of rationality. This is one in which agents realize that they cannot possibly understand the "whole picture". As a result they use relatively simple rules (heuristics). Rationality comes into play when these agents subject these rules ex post to a fitness (profitability) test and are willing to switch to the more profitable rule.

We used this framework and applied it to the foreign exchange market. We extended previous analysis in two ways. First, we allowed agents to use many different forecasting rules, instead of just two. Second, we assumed that agents have imperfect knowledge of the underlying fundamental. As a result, different agents come up with different estimates of the fundamental exchange rate.

Our results confirm the existence of two types of equilibria, a fundamental and a nonfundamental (bubble) one. The exchange rate switches from one equilibrium to the other as a result of stochastic disturbances. This creates cyclical movements of the exchange rate around the fundamental. This result is not sensitive to the number of forecasting rules among which agents can choose. ${ }^{15}$

Secondly, we found that the exchange rate dynamics is sensitive to initial conditions. This means that a small initial disturbance to the exchange rate can change its future time path in a drastic way, creating new cycles that are not present without the initial disturbance. However, we found that this result is sensitive to the number of forecasting rules agents can choose from. We also find that the probability of switching between equilibria does depend on the number of rules. Both results have to do with the fact that with a higher number of rules the discontinuities in the switches between rules becomes less pronounced.

We also analyzed how uncertainty about the underlying fundamental exchange rate affects the dynamics in the market. We found that when agents change the confidence they have about their estimate of the fundamental exchange, the time path of the exchange rate is affected strongly.

Finally, we our model produces excess volatility, a feature that has also been observed

\footnotetext{
${ }^{15}$ We stress that we have simulated the model with a maximum of 200 forecasting rules. This conclussion might not necessarily apply if the number of rules is further increased.
} 
in real life data. The degree of excess volatility depends on the number of rules agents can choose from and on the uncertainty they face about the underlying fundamental.

\section{Appendix A: Solution of the model}

In this appendix we investigate the properties of the solution of a simplified version of the model in which we assume that there are only two forecasting rules, i.e. one fundamentalist rule and one chartist (extrapolative rule).

\section{The steady state}

The non-linear structure of our model does not allow for a simple analytical solution. We set $Z=0$, and normalize the fundamental rate, $s_{t}^{*}=s^{*}=0$. We can then write equation 6 as follows:

$$
s_{t}=s_{t-1}-\Theta_{f, t} \psi s_{t-1}+\Theta_{c, t} \beta\left(s_{t-1}-s_{t-2}\right)
$$

where

$$
\Theta_{f, t}=\frac{w_{f, t} / \sigma_{f, t}^{2}}{w_{f, t} / \sigma_{f, t}^{2}+w_{c, t} / \sigma_{c, t}^{2}}
$$

and

$$
\Theta_{c, t}=\frac{w_{c, t} / \sigma_{c, t}^{2}}{w_{f, t} / \sigma_{f, t}^{2}+w_{c, t} / \sigma_{c, t}^{2}}
$$

are the risk adjusted weights of fundamentalists and technical traders, and

$$
w_{f, t}=\frac{\exp \left[\gamma \pi_{f, t-1}-\mu \sigma_{f, t}^{2}\right]}{\exp \left[\gamma \pi_{c, t-1}-\mu \sigma_{c, t}^{2}\right]+\exp \left[\gamma \pi_{f, t-1}-\mu \sigma_{f, t}^{2}\right]}
$$

Equations 13 and 14 defining the variance terms can also be rewritten as follows:

$$
\begin{gathered}
\sigma_{c, t}^{2}=(1-\theta) \sigma_{c, t-1}^{2}+\theta\left[E_{t-2}^{c}\left(s_{t-1}\right)-s_{t-1}\right]^{2} \\
\sigma_{f, t}^{2}=(1-\theta) \sigma_{f, t-1}^{2}+\theta\left[E_{t-2}^{f}\left(s_{t-1}\right)-s_{t-1}\right]^{2}
\end{gathered}
$$


Using the definition of the forecasting rules 8 and 9 , this yields

$$
\begin{gathered}
\sigma_{c, t}^{2}=(1-\theta) \sigma_{c, t-1}^{2}+\theta\left[(1+\beta) s_{t-3}-\beta s_{t-2}-s_{t-1}\right]^{2} \\
\sigma_{f, t}^{2}=(1-\theta) \sigma_{f, t-1}^{2}+\theta\left[(1-\psi) s_{t-2}-s_{t-1}\right]^{2}
\end{gathered}
$$

With suitable changes of variables it is possible to write the system as a 6-dimensional system. Set

$$
\begin{gathered}
u_{t}=s_{t-1} \\
x_{t}=u_{t-1}\left(=s_{t-2}\right)
\end{gathered}
$$

The 6 dynamic variables are $\left(s_{t}, u_{t}, x_{t}, \pi_{c, t}, \sigma_{c, t}^{2}, \sigma_{f, t}^{2}\right)$. The state of the system at time $t-1$, i.e. $\left(s_{t-1}, u_{t-1}, x_{t-1}, z_{t-1}, \pi_{c, t-1}, \sigma_{c, t-1}^{2}, \sigma_{f, t-1}^{2}\right)$ determines the state of the system at time $t$, i.e. $\left(s_{t}, u_{t}, x_{t}, \pi_{c, t}, \sigma_{c, t}^{2}, \sigma_{f, t}^{2}\right)$ through the following 6 -D dynamic system:

$$
\begin{gathered}
s_{t}=\left[1+\beta-\Theta_{f, t}(\psi+\beta)\right] s_{t-1}-\left(1-\Theta_{f, t}\right) \beta u_{t-1} \\
u_{t}=s_{t-1} \\
x_{t}=u_{t-1} \\
\pi_{c, t}=\left(s_{t}-s_{t-1}\right) \operatorname{sgn}\left[\left(u_{t-1}+\beta\left(u_{t-1}-x_{t-1}\right)-s_{t-1}\right)\left(s_{t}-s_{t-1}\right)\right] \\
\sigma_{c, t}^{2}=(1-\theta) \sigma_{c, t-1}^{2}+\theta\left[(1+\beta) u_{t-1}-\beta x_{t-1}-s_{t-1}\right]^{2} \\
\sigma_{f, t}^{2}=(1-\theta) \sigma_{f, t-1}^{2}+\theta\left[(1-\psi) u_{t-1}-s_{t-1}\right]^{2}
\end{gathered}
$$

where

$$
\Theta_{f, t}=\frac{w_{f, t} / \sigma_{f, t}^{2}}{w_{f, t} / \sigma_{f, t}^{2}+w_{c, t} / \sigma_{c, t}^{2}}
$$

and

$$
w_{f, t}=\frac{\exp \left[\gamma \pi_{f, t-1}-\mu \sigma_{f, t}^{2}\right]}{\exp \left[\gamma \pi_{c, t-1}-\mu \sigma_{c, t}^{2}\right]+\exp \left[\gamma \pi_{f, t-1}-\mu \sigma_{f, t}^{2}\right]}
$$




$$
\pi_{f, t-1}=\left(s_{t-1}-u_{t-1}\right) \operatorname{sgn}\left[\left((1-\psi) x_{t-1}-u_{t-1}\right)\left(s_{t-1}-u_{t-1}\right)\right]
$$

It can now be shown that the model produces two types of steady state solutions. We analyze these consecutively.

\section{The exchange rate equals the fundamental value.}

We normalize the fundamental to be zero. Thus, this solution implies that $s_{t}=0$. As a result, the variance terms go to zero. This also means that in the steady state, the risk adjusted weights of the fundamentalists and chartists are of the form $\Theta_{f, t}=\frac{\infty}{\infty}$ and $\Theta_{c, t}=\frac{\infty}{\infty}$.

Rewriting these weights as follows:

$$
\Theta_{f, t}=\frac{w_{f, t}}{w_{f, t}+w_{c, t}\left(\sigma_{f, t}^{2} / \sigma_{c, t}^{2}\right)}
$$

and

$$
\Theta_{c, t}=\frac{w_{c, t}\left(\sigma_{f, t}^{2} / \sigma_{c, t}^{2}\right)}{w_{f, t}+w_{c, t}\left(\sigma_{f, t}^{2} / \sigma_{c, t}^{2}\right)}
$$

One can show by numerical methods that in the steady state the expression $\sigma_{f, t}^{2} / \sigma_{c, t}^{2}$ converges to $1 .{ }^{16}$ We show this in appendix 1 where we plot the ratio as a function of time. This implies that in the steady state $\Theta_{f, t}=w_{f, t}$ and $\Theta_{c, t}=w_{c, t} \cdot\left(\right.$ Note that $\left.w_{f, t}+w_{c, t}=1\right)$.

The steady state of the system is now obtained by setting

$$
\left(s_{t-1}, u_{t-1}, x_{t-1}, \pi_{c, t-1}, \sigma_{f, t-1}^{2}, \sigma_{c, t-1}^{2}\right)=\left(s_{t}, u_{t}, x_{t}, \pi_{c, t}, \sigma_{f, t}^{2}, \sigma_{c, t}^{2}\right)=\left(\bar{s}, \bar{u}, \bar{x}, \bar{\pi}_{c}, \bar{\sigma}_{f}^{2}, \bar{\sigma}_{c}^{2}\right)
$$

in the dynamic system (28)-(33).

There is a unique steady state where

$$
\bar{s}, \bar{u}, \bar{x}=0, \bar{\pi}_{c}=0, \bar{\sigma}_{f}^{2}, \bar{\sigma}_{c}^{2}=0
$$

Notice also that at the steady state

$$
\bar{w}_{c}=\frac{1}{2}, \bar{w}_{f}=\frac{1}{2}, \bar{\pi}_{f}=0
$$

i.e. the steady state is characterized by the exchange rate being at its fundamental level, by zero profits and zero risk, and by fundamentalist and technical trader fractions equal to $\frac{1}{2}$.

\footnotetext{
${ }^{16}$ It does not appear to be possible to show this by analytical methods.
} 


\section{The exchange rate equals a non-fundamental value}

The model allows for a second type of steady state solution. This is a solution in which the exchange rate is constant and permanently different from its (constant) fundamental value. In other words the model allows for a constant non-zero exchange rate in the steady state.

The existence of such an equilibrium can be shown as follows. We use 20 and set $s_{t}=$ $s_{t-1}=s_{t-2}=\bar{s}$, so that

$$
-\Theta_{f, t} \psi \bar{s}=0
$$

It can now easily be seen that if $\Theta_{f, t}=0$, any constant exchange rate will satisfy this equation. From the definition of $\Theta_{f, t}$ we find that a sufficient condition for $\Theta_{f, t}$ to be zero is that $\sigma_{f, t}^{2}=\bar{\sigma}_{f}^{2}>0$, and $\sigma_{c, t}^{2}=\bar{\sigma}_{c}^{2}=0$. Note that in this case $\Theta_{c, t}=1$ and $\bar{\sigma}_{f}^{2}=$ $\psi^{2} \bar{s}^{2}$. Put differently, there exist fixed point equilibria in the steady state with the following characteristics: the exchange rate deviates from the fundamental by a constant amount; thus, fundamentalist forecasting rules lead to a constant error and therefore the risk adjusted share of fundamentalist rules is zero. ${ }^{17}$ The latter is necessary, otherwise agents would still be using the rule so that their forecast of a reversion to the fundamental would move the exchange rate.

We will call this non-fundamental equilibrium a bubble equilibrium. We call it a bubble equilibrium because it is an equilibrium in which fundamentalists exert no influence on the exchange rate. It should be stressed that this definition of a bubble is very different from the "rational bubble" which is defined as an unstable path of the exchange rate. It comes closer to the notion of "sunspots" which is also an equilibrium concept in rational expectations models (see Blanchard and Fischer(1989), p255).

With this dynamic system it is not possible to perform the local stability analysis of the steady state with the usual techniques, based upon the analysis of the eigenvalues of the Jacobian matrix evaluated at the steady state. The reason is that the "map" whose iteration generates the dynamics is not differentiable at the steady state (in fact the map is not differentiable, for instance, on the locus of the phase-space of equation $s=u$, and the

\footnotetext{
${ }^{17}$ Note that this does not imply that the share of the fundamentalists, $w_{f, t}=0$ as can be seen from equation (35).
} 
steady state belongs to this subset of the phase space).

\section{Appendix B: Other equilibria}

We have analyzed fixed point equilibria in the main text. These are obtained for a wide set of plausible parameter values, but not for all. There are parameter values for which we obtain periodic solutions instead of fixed points. There are also parameter values that generate more complex solutions. We analyze these solutions in the present appendix.

Figure 12: Chaotic behavior: STMA $=\mathbf{5}-$ LTMA $=10$

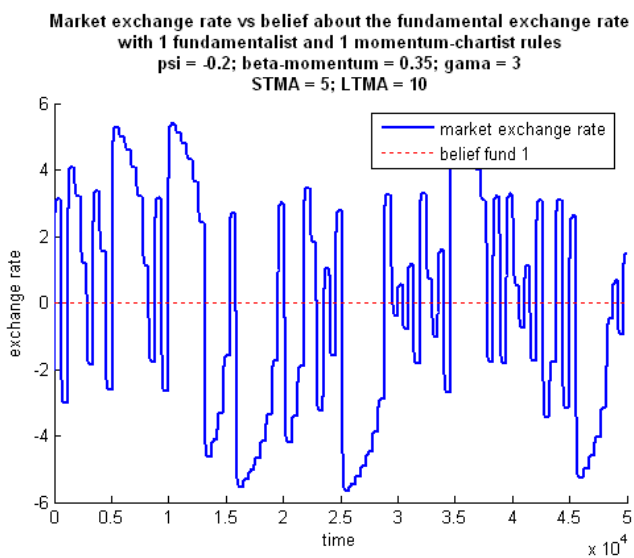

$12 \mathrm{a}$

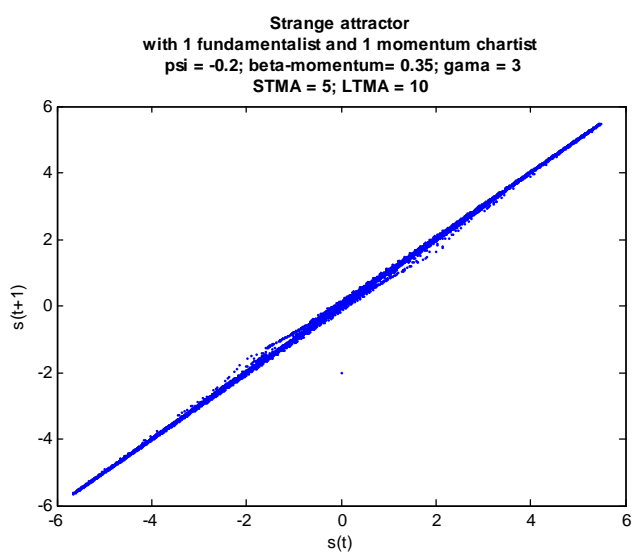

$12 \mathrm{~b}$

Figure 13: Chaotic behavior: STMA $=\mathbf{5}-$ LTMA $=15$

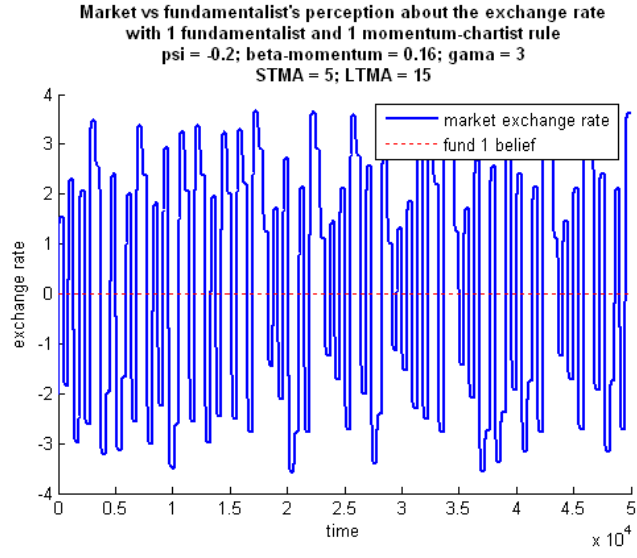

$13 \mathrm{a}$

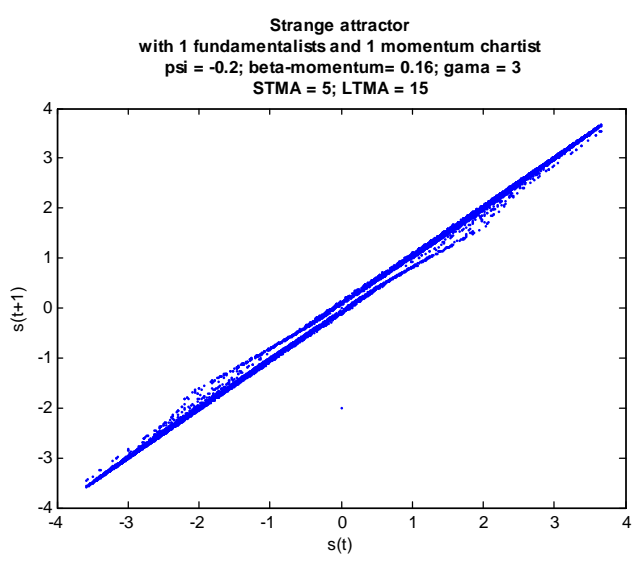

$13 \mathrm{~b}$ 
We find that some parameter values create the conditions for chaotic behavior. In general, the range of parameter values that create chaos, however, is rather small. We show an example of chaotic behavior in figure 11a which shows the exchange rate in the time domain. We have used the deterministic version of the model to create this simulation. We observe cyclical movements around the fundamental. These movements are not the results of stochastics, as all stochastics was eliminated from the model. In Figure 11b we show the strange attractor corresponding to this simulation. As will be remembered, the strange attractor is the plot of $s_{t}$ and $s_{t-1}$ (phase space representation). We observe that the exchange rate does not settle to a fixed point but is contained into a "strange attractor". In figures $12 \mathrm{a}$ and $12 \mathrm{~b}$ we show another example of complex dynamics both in the time domain and in the phase space.

\section{References}

[1] Anderson, S., de Palma, A. and Thiesse J.-F. (1992). Discrete Choice Theory of Product Differentiation. Cambridge, MA: MIT Press.

[2] Blanchard, O.J. and Fischer, S. (1989). Lectures in Macroeconomics. Cambridge, MA: MIT Press.

[3] Brock, W. and Hommes, C. (1995). A Rational Route to Randomness. Econometrica, 65: 1059-1095.

[4] Brock, W. and Hommes, C. (1998). Heterogeneous beliefs and routes to chaos in a simple asset pricing model. Journal of Economic Dynamics and Control 22:1235-1274.

[5] Brunnermeier, M. 2001. Asset Pricing under Asymmetric Information: Bubbles, Crashes, Technical Analysis, and Herding. Oxford University Press.

[6] De Grauwe, P. and Grimaldi, M. (2005). Heterogeneity of agents, transaction costs and the exchange rate. Journal of Economic Dynamics and Control, 29: 691-719.

[7] — (2006). The Exchange Rate in a Behavioral Finance Framework. Princeton, NJ: Princeton University Press. 
[8] Frankel, J., and Froot, (1990). Chartists, fundamentalists and trading in the foreign exchange market. American Economic Review 80:181-185.

[9] Kahneman, D., Knetsch, J. and Thaler, R. (1991). The Endowment Effect, Loss Aversion and Status Quo Bias. Journal of Economic Perspectives, 5: 193-206.

[10] Kahneman, D. and Thaler, R. H. (2006). Utility Maximization and Experienced Utility, Journal of Economic Perspectives, 20(1), 221-234.

[11] Kirman, A. and G. Teyssière. 2002. Microeconomic models for long memory in the volatility of financial time series. Studies in Nonlinear Dynamics and Econometrics 5:137-156,

[12] 281-302.

[13] Lux, T. (1998). The Socio-Economic Dynamics of Speculative Markets: Interacting Agents, Chaos, and Fat Tails of Return Distributions. Journal of Economic Behavior E Organization, 33: 143-165.

[14] Lux, T. and Marchesi, M., (1999). Scaling and Criticality in a Stochastic Multi_Agent Model of a Financial Market, Letters to Nature, 397, 498 - 500

[15] Lux, T. and S. Schorstein. (2005). Genetic learning as an explanation of stylized facts of foreign exchange markets. Journal of Mathematical Economics 41:169-196.

[16] Sargent, T. (1993). Bounded Rationality in Macroeconomics. Oxford University Press.

[17] Shiller, R., (2000). Irrational Exuberance. Princeton University Press.

[18] Shleifer, A. (2000). Introduction to Behavioural Finance. Oxford: Clarendon.

[19] Simon, H. (1957). Models of Man. NewYork: JohnWiley.

[20] Taylor, M. and H. Allen. (1992). The use of technical analysis in the foreign exchange market. Journal of International Money and Finance 11:304-314.

[21] Thaler, R. (1994). Quasi Rational Economics. NewYork: Russell Sage Foundation. 
[22] Tversky, A. and D. Kahneman. 1981. The framing of decisions and the psychology of choice. Science 211:453-458. 


\title{
CESifo Working Paper Series
}

\author{
(for full list see www.cesifo-group.de)
}

1788 George Kapetanios, M. Hashem Pesaran and Takashi Yamagata, Panels with Nonstationary Multifactor Error Structures, August 2006

1789 Torben M. Andersen, Increasing Longevity and Social Security Reforms, August 2006

1790 John Whalley, Recent Regional Agreements: Why so many, why so much Variance in Form, why Coming so fast, and where are they Headed?, August 2006

1791 Sebastian G. Kessing and Kai A. Konrad, Time Consistency and Bureaucratic Budget Competition, August 2006

1792 Bertil Holmlund, Qian Liu and Oskar Nordström Skans, Mind the Gap? Estimating the Effects of Postponing Higher Education, August 2006

1793 Peter Birch Sørensen, Can Capital Income Taxes Survive? And Should They?, August 2006

1794 Michael Kosfeld, Akira Okada and Arno Riedl, Institution Formation in Public Goods Games, September 2006

1795 Marcel Gérard, Reforming the Taxation of Multijurisdictional Enterprises in Europe, a Tentative Appraisal, September 2006

1796 Louis Eeckhoudt, Béatrice Rey and Harris Schlesinger, A Good Sign for Multivariate Risk Taking, September 2006

1797 Dominique M. Gross and Nicolas Schmitt, Why do Low- and High-Skill Workers Migrate? Flow Evidence from France, September 2006

1798 Dan Bernhardt, Stefan Krasa and Mattias Polborn, Political Polarization and the Electoral Effects of Media Bias, September 2006

1799 Pierre Pestieau and Motohiro Sato, Estate Taxation with Both Accidental and Planned Bequests, September 2006

1800 Øystein Foros and Hans Jarle Kind, Do Slotting Allowances Harm Retail Competition?, September 2006

1801 Tobias Lindhe and Jan Södersten, The Equity Trap, the Cost of Capital and the Firm’s Growth Path, September 2006

1802 Wolfgang Buchholz, Richard Cornes and Wolfgang Peters, Existence, Uniqueness and Some Comparative Statics for Ratio- and Lindahl Equilibria: New Wine in Old Bottles, September 2006 
1803 Jan Schnellenbach, Lars P. Feld and Christoph Schaltegger, The Impact of Referendums on the Centralisation of Public Goods Provision: A Political Economy Approach, September 2006

1804 David-Jan Jansen and Jakob de Haan, Does ECB Communication Help in Predicting its Interest Rate Decisions?, September 2006

1805 Jerome L. Stein, United States Current Account Deficits: A Stochastic Optimal Control Analysis, September 2006

1806 Friedrich Schneider, Shadow Economies and Corruption all over the World: What do we really Know?, September 2006

1807 Joerg Lingens and Klaus Waelde, Pareto-Improving Unemployment Policies, September 2006

1808 Axel Dreher, Jan-Egbert Sturm and James Raymond Vreeland, Does Membership on the UN Security Council Influence IMF Decisions? Evidence from Panel Data, September 2006

1809 Prabir De, Regional Trade in Northeast Asia: Why do Trade Costs Matter?, September 2006

1810 Antonis Adam and Thomas Moutos, A Politico-Economic Analysis of Minimum Wages and Wage Subsidies, September 2006

1811 Guglielmo Maria Caporale and Christoph Hanck, Cointegration Tests of PPP: Do they also Exhibit Erratic Behaviour?, September 2006

1812 Robert S. Chirinko and Hisham Foad, Noise vs. News in Equity Returns, September 2006

1813 Oliver Huelsewig, Eric Mayer and Timo Wollmershaeuser, Bank Behavior and the Cost Channel of Monetary Transmission, September 2006

1814 Michael S. Michael, Are Migration Policies that Induce Skilled (Unskilled) Migration Beneficial (Harmful) for the Host Country?, September 2006

1815 Eytan Sheshinski, Optimum Commodity Taxation in Pooling Equilibria, October 2006

1816 Gottfried Haber and Reinhard Neck, Sustainability of Austrian Public Debt: A Political Economy Perspective, October 2006

1817 Thiess Buettner, Michael Overesch, Ulrich Schreiber and Georg Wamser, The Impact of Thin-Capitalization Rules on Multinationals' Financing and Investment Decisions, October 2006

1818 Eric O’N. Fisher and Sharon L. May, Relativity in Trade Theory: Towards a Solution to the Mystery of Missing Trade, October 2006 
1819 Junichi Minagawa and Thorsten Upmann, Labor Supply and the Demand for Child Care: An Intertemporal Approach, October 2006

1820 Jan K. Brueckner and Raquel Girvin, Airport Noise Regulation, Airline Service Quality, and Social Welfare, October 2006

1821 Sijbren Cnossen, Alcohol Taxation and Regulation in the European Union, October 2006

1822 Frederick van der Ploeg, Sustainable Social Spending in a Greying Economy with Stagnant Public Services: Baumol’s Cost Disease Revisited, October 2006

1823 Steven Brakman, Harry Garretsen and Charles van Marrewijk, Cross-Border Mergers \& Acquisitions: The Facts as a Guide for International Economics, October 2006

1824 J. Atsu Amegashie, A Psychological Game with Interdependent Preference Types, October 2006

1825 Kurt R. Brekke, Ingrid Koenigbauer and Odd Rune Straume, Reference Pricing of Pharmaceuticals, October 2006

1826 Sean Holly, M. Hashem Pesaran and Takashi Yamagata, A Spatio-Temporal Model of House Prices in the US, October 2006

1827 Margarita Katsimi and Thomas Moutos, Inequality and the US Import Demand Function, October 2006

1828 Eytan Sheshinski, Longevity and Aggregate Savings, October 2006

1829 Momi Dahan and Udi Nisan, Low Take-up Rates: The Role of Information, October 2006

1830 Dieter Urban, Multilateral Investment Agreement in a Political Equilibrium, October 2006

1831 Jan Bouckaert and Hans Degryse, Opt In Versus Opt Out: A Free-Entry Analysis of Privacy Policies, October 2006

1832 Wolfram F. Richter, Taxing Human Capital Efficiently: The Double Dividend of Taxing Non-qualified Labour more Heavily than Qualified Labour, October 2006

1833 Alberto Chong and Mark Gradstein, Who's Afraid of Foreign Aid? The Donors' Perspective, October 2006

1834 Dirk Schindler, Optimal Income Taxation with a Risky Asset - The Triple Income Tax, October 2006

1835 Andy Snell and Jonathan P. Thomas, Labour Contracts, Equal Treatment and WageUnemployment Dynamics, October 2006 
1836 Peter Backé and Cezary Wójcik, Catching-up and Credit Booms in Central and Eastern European EU Member States and Acceding Countries: An Interpretation within the New Neoclassical Synthesis Framework, October 2006

1837 Lars P. Feld, Justina A.V. Fischer and Gebhard Kirchgaessner, The Effect of Direct Democracy on Income Redistribution: Evidence for Switzerland, October 2006

1838 Michael Rauscher, Voluntary Emission Reductions, Social Rewards, and Environmental Policy, November 2006

1839 Vincent Vicard, Trade, Conflicts, and Political Integration: the Regional Interplays, November 2006

1840 Erkki Koskela and Mikko Puhakka, Stability and Dynamics in an Overlapping Generations Economy under Flexible Wage Negotiation and Capital Accumulation, November 2006

1841 Thiess Buettner, Michael Overesch, Ulrich Schreiber and Georg Wamser, Taxation and Capital Structure Choice - Evidence from a Panel of German Multinationals, November 2006

1842 Guglielmo Maria Caporale and Alexandros Kontonikas, The Euro and Inflation Uncertainty in the European Monetary Union, November 2006

1843 Jan K. Brueckner and Ann G. Largey, Social Interaction and Urban Sprawl, November 2006

1844 Eytan Sheshinski, Differentiated Annuities in a Pooling Equilibrium, November 2006

1845 Marc Suhrcke and Dieter Urban, Are Cardiovascular Diseases Bad for Economic Growth?, November 2006

1846 Sam Bucovetsky and Andreas Haufler, Preferential Tax Regimes with Asymmetric Countries, November 2006

1847 Luca Anderlini, Leonardo Felli and Andrew Postlewaite, Should Courts always Enforce what Contracting Parties Write?, November 2006

1848 Katharina Sailer, Searching the eBay Marketplace, November 2006

1849 Paul De Grauwe and Pablo Rovira Kaltwasser, A Behavioral Finance Model of the Exchange Rate with Many Forecasting Rules, November 2006 